\title{
LUT
}

University

Two alternative process routes for recovering pure indium from waste liquid crystal display panels

Virolainen Sami, Huhtanen Tommi, Laitinen Antero, Sainio Tuomo

This is a Author's accepted manuscript (AAM) version of a publication

published by Elsevier

in Journal of Cleaner Production

DOI: $\quad 10.1016 /$ j.jclepro.2019.118599

Copyright of the original publication: (c) 2019 Elsevier Ltd.

Please cite the publication as follows:

Virolainen, S., Huhtanen, T., Laitinen, A., Sainio, T., 2020. Two alternative process routes for recovering pure indium from waste liquid crystal display panels. Journal of Cleaner Production 243, 118599. https://doi.org/10.1016/j.jclepro.2019.118599

This is a parallel published version of an original publication.

This version can differ from the original published article. 
Virolainen, S., Huhtanen, T., Laitinen, A., Sainio, T., 2020.

\section{Two alternative process routes for recovering pure indium from waste liquid crystal display panels}

Journal of Cleaner Production 243, 118599.

https://doi.org/10.1016/j.jclepro.2019.118599 


\begin{abstract}
Recovering indium from liquid crystal display (LCD) screen waste is important from a sustainability point of view for several reasons: the environmentally hazardous metals are not landfilled, the recovery process involves lower $\mathrm{CO}_{2}$ emissions than primary production, and supply from secondary sources matches the continuously increasing demand of indium. In this study, two alternative process routes for recycling the critical metal, indium, from LCD panel waste were studied and compared using laboratory and bench-scale experiments. The first process was a conventional hydrometallurgical process that involves manual dismantling, hammer mill crushing of the glass, cross-current sulfuric acid leaching of the metals, and liquid-liquid extraction separation of indium. Using this process, over $99 \%$ pure indium solution can be produced with a recovery yield of over $70 \%$. The second process is novel because it includes (manual) scraping of the indium tin oxide (ITO) layer from the glass panels, followed by sulfuric acid leaching of the metals. The yield of indium was over $80 \%$, and the purity of the resulting solution was over $99 \%$. The solutions obtained from either of the suggested processes were sufficiently pure for cementing indium in high purity. The novel process appears much more straightforward and economically more feasible because the polarizing filter need not be removed and the liquid-liquid extraction purification step is excluded. Moreover, less amount of leaching acid is required.
\end{abstract}

\title{
Keywords
}

Indium; Indium tin oxide (ITO); LCD panels; Physical separation; Hydrometallurgy; Bench-scale 


\section{List of Abbreviations}

D2EHPA Di-2-(ethylhexyl) phosphoric acid

Exxsol D80 Kerosene diluent

$\mathrm{Fe}(\mathrm{II}) \quad$ Divalent iron (ferrous iron)

$\mathrm{Fe}(\mathrm{III}) \quad$ Trivalent iron (ferric iron)

$\mathrm{HCl} \quad$ Hydrochloric acid

$\mathrm{HNO}_{3} \quad$ Nitric acid

$\mathrm{H}_{2} \mathrm{SO}_{4} \quad$ Sulfuric acid

ICP-MS Inductively Coupled Plasma - Mass Spectrometry

ITO Indium Tin Oxide

L/S Liquid to solid ratio in leaching determined as volume/mass

LCD Liquid crystal display

$\mathrm{Na}_{2} \mathrm{SO}_{3} \quad$ Sodium sulfite

$\mathrm{O} / \mathrm{A} \quad$ Volumetric phase ratio between organic and aqueous phase in liquid-liquid extraction

TBP Tributylphosphate

WEEE Waste Electrical and Electronic Equipment 


\section{Introduction}

In 2016, 44.7 Mt of E-waste was generated worldwide, from which 6.6 Mt was categorized as screens (televisions, monitors, laptops, notebooks, and tablets; Baldé et al., 2017). The number does not include cell phones, which account for a few more percentages. Additionally, 9.5 wt.-\% of the mass of screen devices is glass (Lee and Cooper, 2008).

The rapidly increasing amount of LCD screen waste has created an increasingly serious waste management problem. Like with many types of Waste Electrical and Electronic Equipment (WEEE), landfilling LCD waste will cause heavy metals to gradually leach into soil, groundwater, and surface water (Javad Jowkar et al., 2018). However, it is generally known that utilizing secondary raw materials instead of primary ores as a source of metals is often resource efficient from energy consumption, environmental and economic points of view (Virolainen, 2013). For example, $\mathrm{CO}_{2}$ emissions from the recovery process are up to $600 \mathrm{kgCO}_{2} / \mathrm{kg}$ indium lower for the recycling process from LCD screens compared to primary production (Rocchetti et al., 2015). The aforementioned reasons make development of an indium recovery process for LCD screen waste important to provide sustainability and cleaner production. Additionally, the indium content in LCD screens is higher than in mined ores (Virolainen, 2013).

Indium is a critical metal (European Commission, 2017) used mainly as indium tin oxide (ITO) films in LCD panels, which is based on its suitable semiconducting and transparent properties. Indium has no own ores, and its primary production is based on its recovery as a by-product in hydrometallurgical zinc production outside of Europe (Werner et al., 2017). 
The indium content in LCD glass panels is typically 200-261 mg/kg (Ma et al., 2013; Yang et al., 2013; Lee at al., 2013), but some panels may contain only $50-130 \mathrm{mg} / \mathrm{kg}$ (Rocchetti et al., 2015; Wang, 2009) or even $380-410 \mathrm{mg} / \mathrm{kg}$ of indium (Hasegawa et al., 2013). The deviation is caused by large differences in thicknesses of the ITO layers in panels (30-2990 $\mathrm{nm}$ ). The typical thickness of the ITO layer is $125 \mathrm{~nm}$, which corresponds to $234 \mathrm{mg} / \mathrm{m}^{2}$ of indium content (Böni et al., 2011). As the demand of indium has increased during recent decades, the amount of screen waste has increased substantially, and it has become an alternative indium source that can relieve supply problems. Based on the above given numbers regarding LCD waste material flows and indium contents in panels, it can be estimated that the 2016 estimate of the amount of indium in LCD panel waste, as calculated with $200 \mathrm{mg} / \mathrm{kg}$ of indium content, was $125 \mathrm{t}$ worldwide, while the primary indium production was $655 \mathrm{t}$ (United States Geological Survey, 2017). It has been stated that owing to increasing demand, recycled indium from LCDs will likely be needed in the future (Wang et al., 2015; Ferrella et al., 2017; Javad Jowkar et al., 2018).

Although recovering indium from waste panels has been studied extensively over the past ten years, industrial recycling processes have yet to be built. In 2011, the recycling rate of indium from LCD screen waste was $<1 \%$ (Graedel et al., 2011). The challenge lies in collecting, transporting, and processing large amounts of material to recover relatively small amounts of indium.

During the past two years, many new processes to improve the technical, economical, and environmental feasibility of indium recycling from LCD panels have been suggested in the academic literature. Ferella et al. (2017) recovered indium quantitatively by leaching fractions obtained using physico-mechanical treatment with $\mathrm{H}_{2} \mathrm{SO}_{4}$ and subsequent 
recovery with a chelating iminodiacetic acid resin. Similarly, Assefi et al. (2018) concluded that the iminodiacetic acid resin is the most efficient among few chelating resins for recovering indium from a $\mathrm{HCl}-\mathrm{HNO}_{3}$ mixture leachate. Argenta et al. (2017) reported enhanced leaching recoveries by using organic acids at supercritical $\mathrm{CO}_{2}$ conditions. However, for these processes, the purities of the recovered indium products were not studied.

Lingen Zhang and co-workers (Chen et al., 2017; Zhang et al., 2017a and b; Zhang and $\mathrm{Xu}, 2017$; Zhang et al., 2018) proposed a process of mechanical stripping of ITO film followed by vacuum pyrolysis. Up to $78 \%$ pure indium product in a $98 \%$ yield was obtained. In particular, the mechanical scrubbing step is efficient, and it is a selective method for removing the ITO film from the surface of a glass panel. Attrition scrubbing of an ITO film has been studied as a simple process to recover indium in which the enrichment of indium to $2000 \mathrm{mg} / \mathrm{kg}$ with a $90 \%$ recovery yield was reported (Boundy et al., 2017).

One interesting approach to improving the logistical drawbacks related to recycling has been proposed by Rocchetti et al. (2013), who designed a plant-on-wheels-type of relocatable process to recover indium from LCD panels. It has been shown that transport costs are much lower when the process is moved to the raw materials, rather than moving the raw materials to the process. The process detailed by Rocchetti et al. (2015) includes shredding as a pretreatment, leaching of metals from the shredded glass with $\mathrm{H}_{2} \mathrm{SO}_{4}$, and direct cementation using zinc powder (Rocchetti et al., 2016). Unfortunately, the process only yielded slightly over $60 \%$ indium purity, indicating the need for a purification step to obtain high-purity indium metal, for which $4 \mathrm{~N}$ (i.e., 99.99\%) is the market standard (Lokanc et al., 2015). 
One significant detail in LCD panel processing is the removal of the polyvinyl alcohol and cellulose triacetate polarizing film that is attached the top of the glass substrate with acrylic polymer adhesives. For the removal, different chemical and thermal treatment methods have been suggested, e.g., by Fontana et al. (2015).

Liquid-liquid extraction has been suggested almost exclusively for the purification of indium from LCD glass leachate. Di-(2-ethylhexyl) phosphoric acid (D2EHPA) is the most commonly used reagent owing to its high affinity for indium. However, the selectivity for indium over iron, aluminum, and tin is not very high in sulfate media (Yang et al., 2014). With D2EHPA, tributylphosphate (TBP), or a mixture of them, it is possible to extract the impurity metals selectively over indium from $\mathrm{HCl}$ media (Virolainen et al., 2011a). However, it is preferable to leach the metals with $\mathrm{H}_{2} \mathrm{SO}_{4}$, extract them with D2EHPA, and selectively strip the indium using $\mathrm{HCl}$ to obtain a high-purity indium solution (Virolainen et al., 2011a; Yang et al., 2014). From a chemical equilibrium or kinetic point of view, $\mathrm{H}_{2} \mathrm{SO}_{4}, \mathrm{HCl}$, or $\mathrm{HNO}_{3}$ can be used for leaching (Virolainen et al., 2011b); however, the $\mathrm{H}_{2} \mathrm{SO}_{4}$ route is preferred because the leachate is cheap, environment-friendly, equipmentfriendly, and does not leach toxic $\mathrm{As}_{2} \mathrm{O}_{3}$ if present in the crushed LCD glass (Rocchetti et al., 2015). The $\mathrm{As}_{2} \mathrm{O}_{3}$ originates from the glass itself, where it is used as a decolorizing agent, enamel, or a fining agent (European Chemicals Agency, 2010). Additionally, by extracting the metals first with D2EHPA, indium can be concentrated from a typical leachate of $<120 \mathrm{mg} / \mathrm{L}$ to several g/L (Virolainen et al., 2011a; Yang et al., 2013; Rocchetti et al., 2015), making downstream processing easier.

Although many studies have reported on the recovery of indium from LCD panels by using hydrometallurgical methods, no study has implemented the entire hydrometallurgical 
process from the authentic LCD glass raw material to the pure indium solution. In this study, however, the following process is demonstrated on a bench-scale:

1. Polarizing filters are manually removed

2. The LCD glass is crushed with a hammer mill

3. Metals are leached with $\mathrm{H}_{2} \mathrm{SO}_{4}$ in a batch reactor in a cross-current configuration

4. Indium is purified and concentrated by extracting it with D2EHPA and selectively stripping it with $\mathrm{HCl}$.

In addition, a process of manually scraping the ITO film from the LCD panels, followed by leaching the obtained material with $\mathrm{H}_{2} \mathrm{SO}_{4}$ to obtain pure and concentrated indium solution for cementation, was studied for the first time.

\section{Materials and methods}

\section{$2.1 \quad$ Materials and chemicals}

LCD panel waste from different types of LCD screen sizes ranging from 15" to 50" were obtained from Kuusakoski Recycling. The glass panels had been manually removed from the used LCD screens.

0.25 M D2EHPA in Exxsol D80 kerosene diluent was used as organic the phase for the liquid-liquid extraction experiments. Before the experiments, the organic phase was washed with $\mathrm{H}_{2} \mathrm{SO}_{4}$ and water and filtered to remove aqueous traces.

Chemicals used in the experimental study included $95 \% \mathrm{H}_{2} \mathrm{SO}_{4}$ (grade: pro analysis, supplier: Merck $\mathrm{KGaA}$ ), $96 \% \mathrm{H}_{2} \mathrm{SO}_{4}$ (technical, Orikem OY), $37 \% \mathrm{HCl}$ (pro analysis, 
VWR International), 67-69\% $\mathrm{HNO}_{3}$ (super purity acid, Romil), D2EHPA (technical, Outotec Oyj), and Exxsol D80 (technical, ExxonMobil).

\subsection{Analytical methods}

Metal concentrations ( $\mathrm{In}, \mathrm{Sn}, \mathrm{Fe}, \mathrm{Cu}, \mathrm{Zn}$, and $\mathrm{Al}$ ) from aqueous solutions were analyzed using ICP-MS (Inductively Coupled Plasma - Mass Spectrometry, device: Agilent 7900) after diluting them with 1 wt.- $\% \mathrm{HNO}_{3}$. The metal contents of solid the samples were analyzed by digesting them with a wet combustion device (Milestone MA149). A 4:1 mixture of concentrated $\mathrm{HNO}_{3}$ and $\mathrm{HCl}$ was used as the digesting reagent, and the sample was kept for $10 \mathrm{~min}$ in $40 \mathrm{bar}$ of pressure at $250^{\circ} \mathrm{C}$.

\subsection{Conventional pretreatment}

Panels removed from the LCD screens consisted of two separate glass sheets. The sheets were separated using a knife, and the liquid crystals between the sheets were wiped away with acetone. The glass sheets were covered by plastic polarizing filters, which were manually removed by hand with the aid of a knife, and the glass was crushed with a Retsch GmbH SK1 hammer mill using an 8-mm sieve.

\subsection{Mechanical scraping of ITO + leaching}

The black matter on the inner surface of the LCD panel, quantitatively containing also the ITO layer, can be scraped off, e.g., by scraping and grinding with a roller brush (Chen $e t$ al., 2017; Zhang et al., 2017a and b; Zhang and Xu, 2017; Zhang et al., 2018). It was decided to systematically study the scraping using six different LCD panels and to analyze 
and leach the "black material" obtained. The scraping was performed manually with steel or a ceramic blade scraper. Four leaching kinetic experiments with $\mathrm{H}_{2} \mathrm{SO}_{4}$ were performed in a $70 \mathrm{~mL}$ jacketed glass reactor. A single-bladed Teflon impeller was used with a 1000 rpm rotation speed.

\subsection{Leaching of LCD glass}

Leaching of the LCD glass in a stirred tank batch reactor can only be performed with a maximum slurry concentration of approximately $30 \%$. Leaching in several batches in a cross-current manner increases the indium concentration in the leachate and reduces consumption of the leaching chemicals (Rasenack and Goldmann, 2014; Rocchetti et al., 2015).

In this study, leaching was performed in three cross-current stages with $1 \mathrm{M} \mathrm{H}_{2} \mathrm{SO}_{4}$ as the leaching reagent and $200 \mathrm{~g} / \mathrm{L}$ as the slurry concentration. Optimization of these was out of the scope of this study, and parameters were chosen based on literature. They were considered to yield sufficient process performance for the qualitative comparison purposes of this study. However, experiments were performed at $22-23{ }^{\circ} \mathrm{C}$ (7 L reactor, $20 \mathrm{~min}$ reaction time) and at $80{ }^{\circ} \mathrm{C}(3 \mathrm{~L}$ jacketed reactor, 15 min reaction time) to check the influence of temperature. 


\subsection{Liquid-liquid extraction}

Continuous counter-current liquid-liquid extraction experiments were performed on a bench-scale by using a cascade of six temperature-controlled mixer-settlers (SX Kinetics, Inc.) with $270 \mathrm{~mL}$ mixers and $1050 \mathrm{~mL}$ settlers. Liquids were fed with MasterFlex 0752830 peristaltic pumps. The rotation speed of the semi-open, six-bladed impellers was 900 $\mathrm{rpm}$. The equipment allowed for accurate adjustment of the aqueous to organic phase ratio (A/O) by recycling the liquids within each mixer-settler unit.

A total of six runs were completed at $T=21-22{ }^{\circ} \mathrm{C}$ (see Table 4). The varied parameters included the number of counter-current stages, the $\mathrm{A} / \mathrm{O}$ phase ratio, and residence time in the mixer $(\tau)$. Stripping of the loaded organic phase with $1 \mathrm{M} \mathrm{HCl}$ was completed in runs 2-4. The fundamentals of this particular liquid-liquid extraction process have been thoroughly studied before (Virolainen et al., 2011a and b; Yang et al., 2013 and 2014); therefore, the purpose of the liquid-liquid extraction experiments was to study those parameters in particular that are important in real continuous-counter current runs (number of stages, $\mathrm{A} / \mathrm{O}$, and $\tau)$ and cannot be easily optimized with the batch equilibrium or kinetic data. For example, the A/O can be determined for the target metal by the McCabe-Thiele method; however, it is very difficult to interpret how the competition rejects the unwanted metals, e.g., iron, in this case. The $\tau$ cannot be optimized based on batch kinetic data because the reactor type is different from a chemical engineering point of view (batch vs. continuous stirred tank reactor).

The phase ratios in the mixers were measured from samples taken near the impeller. The concentrations of the metals were monitored by sampling both aqueous and organic phases. 


\subsection{Quantities used to evaluate the process performance}

In the pretreatment and leaching experiments, the yield of indium, $Y_{\text {In }}(\mathrm{wt}-\%)$, was calculated as the percentage of indium transferred to the target phase, and the purity of indium in the target phase, $P_{\text {In }}(\mathrm{wt}-\%)$, was calculated as the percentage of indium from all the metals.

In liquid-liquid extraction, the extent of extraction was calculated for each metal as

$$
E_{\mathrm{i}}=\frac{c_{\mathrm{i}}^{0}-c_{\mathrm{i}}}{c_{\mathrm{i}}^{0}} \cdot 100 \%
$$

, where $\quad c_{\mathrm{i}}^{0} \quad$ initial concentration of metal $\mathrm{i}, \mathrm{mg} / \mathrm{L}$

$c_{\mathrm{i}} \quad$ concentration of metal $\mathrm{i}$ in equilibrium, $\mathrm{mg} / \mathrm{L}$

and the purity is

$$
P_{\mathrm{In}}=\frac{\overline{c_{\mathrm{In}}}}{\sum_{\mathrm{i}} \overline{c_{\mathrm{i}}}} \cdot 100 \%
$$

, where $\quad \overline{c_{\text {In }}} \quad$ concentration of indium in the organic phase, $\mathrm{mg} / \mathrm{L}$

$c_{\mathrm{i}} \quad$ concentration of metal $\mathrm{i}$ in the organic phase, $\mathrm{mg} / \mathrm{L}$

To describe the extent of reagent utilization in the liquid-liquid extraction, the stoichiometric extent of loading, $S$, was calculated using Eq. 3, where HR stands for the extractant and the overbar denotes the organic phase. The stoichiometric coefficient for metal $\mathrm{i}, n_{\mathrm{i}}$, refers to the number of reagent molecules that one extracted metal atom binds to. The extraction reactions and the corresponding stoichiometric coefficients are given in Table 1.

$$
S=\frac{\sum_{i} \overline{c_{\mathrm{i}}} n_{\mathrm{i}}}{\overline{c_{\mathrm{HR}}}} \cdot 100 \%
$$


Table 1. Extraction reactions in a multicomponent sulfate system with D2EHPA as liquid-liquid extraction reagent.

\begin{tabular}{llll}
\hline Reaction & & $n$ & Reference \\
\hline $\mathrm{In}^{3+}+3 \overline{(\mathrm{HR})_{2}}=\overline{\mathrm{InR}_{3}(\mathrm{HR})_{3}}+3 \mathrm{H}^{+}$ & $(4)$ & 6 & Sato and Sato $(1992)$ \\
$\mathrm{Sn}\left(\mathrm{SO}_{4}\right)_{2}+\overline{(\mathrm{HR})_{2}}=\overline{\mathrm{Sn}\left(\mathrm{SO}_{4}\right)_{2}(\mathrm{HR})_{2}}$ & $(5)$ & 2 & Yang et al. $(2014)$ \\
$\mathrm{Al}^{3+}+3 \overline{(\mathrm{HR})_{2}}=\overline{\mathrm{AlR}_{3}(\mathrm{HR})_{3}}+3 \mathrm{H}^{+}$ & $(6)$ & 6 & Mohapatra et al. $(2007)$ \\
$\mathrm{Fe}\left(\mathrm{SO}_{4}\right)^{+}+\overline{(\mathrm{HR})_{2}}=\overline{\mathrm{Fe}\left(\mathrm{SO}_{4}\right) \mathrm{R}(\mathrm{HR})}+\mathrm{H}^{+}$ & $(7)$ & 2 & Yang et al. (2014) \\
$\mathrm{Cu}^{2+}+2 \overline{(\mathrm{HR})_{2}}=\overline{\mathrm{CuR}_{2}(\mathrm{HR})_{2}}+2 \mathrm{H}^{+}$ & $(8)$ & 4 & Hughes and Kuipa (1996) \\
$\mathrm{Zn}^{2+}+2 \overline{(\mathrm{HR})_{2}}=\overline{\mathrm{ZnR}_{2}(\mathrm{HR})_{2}}+2 \mathrm{H}^{+}$ & $(9)$ & 4 & Raatz and Klapper $(2013)$ \\
\hline
\end{tabular}

\section{Results and discussion}

\subsection{Chemical analysis of raw material LCD panels}

Four LCD panel samples were analyzed using wet combustion followed by ICP-MS (Table 2). The contents of all the samples $(227-296 \mathrm{mg} / \mathrm{kg})$ were similar to those reported in previous studies (Ma and Xu, 2013; Böni et al., 2015; Rocchetti et al., 2015). The ITO film is a 90:10 mixture (by weight) of $\mathrm{In}_{2} \mathrm{O}_{3}$ and $\mathrm{SnO}_{2}$. It was expected that relative amounts of indium and tin in the samples would have been in the same ratio, but higher tin contents were observed. This is in accordance with other studies (Ruan et al., 2012; Rocchetti et al., 2015) and likely originates from the fact that tin is also used in other parts of the LCD panel. 
Table 2. Metal contents of the analyzed LCD glass samples in $\mathrm{mg} / \mathrm{kg}$.

\begin{tabular}{ccccccc}
\hline Sample ID & In & Sn & Al & Fe & Cu & Zn \\
\hline LCD1 & 283 & 35.5 & 1160 & 301 & 9.43 & 27.1 \\
LCD2 & 296 & 63.1 & 1350 & 1110 & 18.5 & 21.2 \\
LCD3 & 227 & 41.2 & 1390 & 342 & 12.5 & 15.7 \\
LCD4 & 281 & 45.8 & 1320 & 516 & 18.5 & 15.3 \\
\hline
\end{tabular}

3.2 Conventional pretreatment + leaching + liquid-liquid extraction process

\subsubsection{Leaching}

According to the aqueous solution chemistry calculations performed with Medusa software (Puigdomenech, 2004) the solubility equilibrium of $\operatorname{In}_{2} \mathrm{O}_{3}$ is very favorable in excess of sulfuric acid. The solubility of $\operatorname{In}_{2}(\mathrm{SO} 4)_{3}$ in water is $539.2 \mathrm{~g} / \mathrm{kg}$ water (Indium Corporation, 2018). The dissolution reactions for indium and tin oxides are (Wiberg et al., 2001):

$$
\begin{aligned}
& \mathrm{In}_{2} \mathrm{O}_{3}(\mathrm{~s})+3 \mathrm{H}_{2} \mathrm{SO}_{4}(\mathrm{~s}) \rightarrow \mathrm{In}_{2}\left(\mathrm{SO}_{4}\right)_{3}(\mathrm{aq})+3 \mathrm{H}_{2} \mathrm{O} \\
& \mathrm{SnO}_{2}(\mathrm{~s})+2 \mathrm{H}_{2} \mathrm{SO}_{4}(\mathrm{aq}) \rightarrow \mathrm{Sn}\left(\mathrm{SO}_{4}\right)(\mathrm{aq})+2 \mathrm{H}_{2} \mathrm{O}
\end{aligned}
$$

Table 3 presents results from six three-stage cross-current leaching experiments. When the temperature was increased from room temperature to $80^{\circ} \mathrm{C}$, the yield of indium increased 4-5 fold (Table 3) owing to enhanced kinetics. Although good indium yields can be obtained at room temperature, it requires days of residence time (Virolainen et al., 2011), making the use of elevated temperatures preferable. With three cross-current leaching stages at $80{ }^{\circ} \mathrm{C}$, the yields were $69-85 \%$ (Table 3). These are comparable to those in Rocchetti et al. (2015), who reported an $80 \%$ yield using a similar method with 10 min of 
residence time for each step. It is thus expected that an over $90 \%$ yield is possible under optimized conditions, but such optimization was out of the scope in this study. Of note, in the experiments of Rocchetti et al. (2015), the yield decreased between the subsequent cross-current stages but not during the experiments ( $c a .95 \%$ yield in the 60 min step) of Rasenack and Goldmann (2014).

In the leachates obtained, the $\mathrm{Sn} / \mathrm{In}$ ratio was approximately 1:10 (see Table 3), which matches their ratio for the ITO film. This indicates that the tin likely present in other parts of the LCD panel was not dissolved during this batch leaching, despite using elevated temperatures.

Brubaker (1955) reported the solubility of tin and its oxides in various sulfuric acid concentrations, and the solubility increased with increasing temperature. At $30{ }^{\circ} \mathrm{C}$, the solubility in $0.96 \mathrm{~mol} / \mathrm{L}$ of $\mathrm{H}_{2} \mathrm{SO}_{4}$ was already $108 \mathrm{mg} / \mathrm{L}$, meaning that equilibrium was not the limiting factor in our case. In experiments conducted by Rocchetti et al. (2015), the $\mathrm{Sn} / \mathrm{In}$ ratio remained high in the leachate; however, the leaching of tin was slower than that of indium. Therefore, the explanation for the lower tin/indium ratio in our study is due to the kinetics (reaction in Eq. (11)). 
Table 3. Three-stage cross-current leaching of metals from LCD glass.

\begin{tabular}{|c|c|c|c|c|c|c|c|c|}
\hline Exp. ID & In & Sn & Al & $\mathbf{F e}$ & $\mathrm{Cu}$ & $\mathbf{Z n}$ & $Y_{\text {In, }} \%$ & $P_{\text {In }}, \%$ \\
\hline \multicolumn{9}{|c|}{$T=22-23{ }^{\circ} \mathrm{C}, t_{\text {step }}=20 \mathrm{~min}$} \\
\hline $\mathrm{L} 1$ & 25.4 & 2.30 & 62.1 & 505 & 1.20 & 2.10 & 16.5 & 4.2 \\
\hline $\mathrm{L} 2$ & 26.4 & 2.20 & 27.1 & 549 & 2.00 & 5.90 & 17.1 & 4.3 \\
\hline \multicolumn{9}{|c|}{$T=80^{\circ} \mathrm{C}, t_{\text {step }}=15 \mathrm{~min}$} \\
\hline L3 & 106 & 8.90 & 77.2 & 449 & 2.00 & 3.50 & 68.8 & 16.4 \\
\hline $\mathrm{L} 4$ & 120 & 10.8 & 82.1 & 366 & 5.50 & 3.30 & 77.8 & 20.4 \\
\hline L5 & 131 & 11.5 & 68.4 & 536 & 4.20 & 2.30 & 85.0 & 17.4 \\
\hline L6 & 122 & 11.0 & 59.1 & 368 & 3.80 & 2.90 & 79.1 & 21.5 \\
\hline
\end{tabular}

Note: Metal concentrations are shown in $\mathrm{mg} / \mathrm{L}$. Slurry at $200 \mathrm{~g} / \mathrm{L}$; leachate is $1 \mathrm{M} \mathrm{H}_{2} \mathrm{SO}_{4}$. The yields were calculated using the average from the four characterization results of the LCD glass samples shown in Table 2. The raw material samples fed to these leaching experiments were not characterized.

The concentrations of iron in the leachate (Table 3) were high compared to the amounts present in the glass powder (Table 2) in each experiment. This phenomenon has not been observed in previous studies (Rocchetti et al., 2015; Ruan et al., 2012; Yang et al., 2013 and 2014). This raises doubt about whether an external source of iron was introduced into the experimental procedure in this study, possibly originating from the steel hammer mill used during crushing. Because iron is known to cause difficulties in the liquid-liquid extraction step, it is recommended to take this into account when making material choices for the equipment used during pretreatment. 


\subsubsection{Liquid-liquid extraction}

The effectiveness of liquid-liquid extraction was evaluated by calculating the extent of extraction for each metal $\left(E_{\mathrm{i}}, \%\right.$, Eq. (1)) and the purity of indium in the organic phase $\left(P_{\mathrm{In}}\right.$, $\%$, Eq. (2)). The results are shown in Table 4 combined with the operating parameters for each run.

Table 4. Continuous counter-current liquid-liquid extraction runs for recovering pure indium from the $\mathrm{H}_{2} \mathrm{SO}_{4}$ leachate of the LCD panel waste.

\begin{tabular}{cccccccccccc}
\hline Exp. \# & Stages & A/O & $\tau, \boldsymbol{m i n}$ & $\boldsymbol{E}_{\mathrm{In}}, \boldsymbol{\%}$ & $\boldsymbol{E}_{\mathrm{Sn}}, \boldsymbol{\%}$ & $\boldsymbol{E}_{\mathrm{Al}}, \boldsymbol{\%}$ & $\boldsymbol{E}_{\mathrm{Fe}}, \boldsymbol{\%}$ & $\boldsymbol{E}_{\mathrm{Cu}}, \boldsymbol{\%}$ & $\boldsymbol{E}_{\mathrm{Zn}}, \boldsymbol{\%}$ & $\boldsymbol{P}_{\mathrm{In}}, \boldsymbol{\%}$ & $\boldsymbol{S}, \boldsymbol{\%}$ \\
\hline L-LE1 & 1 & $1.5: 1$ & 10.0 & 90.4 & 8.60 & 8.40 & 14.9 & 19.9 & 10.4 & 34.2 & 10.0 \\
L-LE2 & 2 & $3.0: 1$ & 10.0 & 99.1 & 60.4 & 39.4 & 25.1 & 38.8 & 45.8 & 46.9 & 20.4 \\
L-LE3 & 2 & $5.0: 1$ & 10.0 & 98.9 & 58.4 & 16.4 & 19.0 & 5.70 & 2.90 & 51.9 & 26.1 \\
L-LE4 & 2 & $3.0: 1$ & 5.0 & 98.6 & 81.2 & 16.2 & 20.3 & 13.7 & 14.5 & 56.1 & 13.6 \\
\hline
\end{tabular}

Note: Feed aqueous phases were $1 \mathrm{M} \mathrm{H}_{2} \mathrm{SO}_{4}$ leachates from the leaching experiments and the contained metals as described in Table 3. Leachate from L3 was the feed to L-LE1, leachate from L4 was the feed to L-LE2, etc.

Table 4 demonstrates that a single stage does not provide a high yield for indium extraction from the LCD glass leachate in a continuous operation (Experiment L-LE1). The extent of extraction remained at $90.4 \%$. The low yield was expected, even though the In-D2EHPA isotherm is very steep (Virolainen et al., 2011a and 2011b), and it is very difficult to achieve under $10 \mathrm{mg} / \mathrm{L}$ raffinate concentrations in single contact without using an $\mathrm{O} / \mathrm{A}$ phase ratio of 1:1 or higher. Although the yields for the co-extracted impurities were also low, the purity of indium in the organic phase was only $34.2 \%$ (16.4\% in the feed leachate).

To improve the extraction of indium, another extraction stage was added to the continuous extraction process, and the $\mathrm{A} / \mathrm{O}$ phase ratio was doubled to 3:1 (Experiment L-LE2). The extraction of indium was satisfactory at over 99\%. The purity of indium increased from 
$20.3 \%$ in the leachate to $46.9 \%$ in the organic phase after extraction. Moreover, the concentration of indium in the loaded organic phase increased. This is a significantly better purification performance than in Experiment L-LE1.

The A/O phase ratio was increased for two reasons. First, by concentrating indium in the organic phase, the volumes of process solutions during downstream processing are lower. Second, creating a stronger competition between the metals for the vacant sites in the reagent increases the purity of indium in the organic phase, which has the highest affinity for D2EHPA, and pushes the other metals to the aqueous phase. Further increasing the A/O phase ratio from $3: 1$ to $5: 1$ increased the purity by a few percentage units to $51.9 \%$ (LLLE3; Table 4).

The stoichiometric extent of loading, $S$, was the highest (26.1\%) in the two-stage run with an A/O phase ratio of 5:1 (L-LE3 in Table 4). The fundamental liquid-liquid extraction data of the particular system show that the selectivity of D2EHPA for indium over iron is minimal (Yang et al., 2013). Therefore, very high A/O phase ratios and multiple stages should be used to achieve significantly better purification. Ruan et al. (2012) tested higher A/O phase ratios, but iron was still extracted in significant quantities. As a conclusion, it is recommended to look for other options to separate indium from iron and aluminum.

It is known that indium can be selectively stripped from D2EHPA over iron, aluminum, and tin with $\mathrm{HCl}$ (Virolainen et al., 2011a and b; Yang et al., 2013), and this route has been suggested to purify indium from LCD glass leachates. In this study, for experimental purposes, the stripping was performed only in a single stage and with $1 \mathrm{M} \mathrm{HCl}$. Therefore, the yields remained low at $26.9 \%$ on average; however, the obtained indium purities were 
very high $(99.5 \%$ on average $)$, i.e., with this experimental set-up, the purity was highlighted over yield. It has been shown, for example, that a $98.8 \%$ purity can be obtained (Yang et al., 2013), and an A/O phase ratio of 1:2 or even lower may be used to decrease the consumption of the stripping solution and increase the indium concentration (Virolainen $e t$ al., 2011a and b). In the article by Virolainen et al. (2011a) article, a 98\% stripping yield was reported, and this yield was used in overall yield calculations in our study. Indium metal can be cemented from the stripping solution with a purity above $99 \%$ because cementation also exhibits some selectivity over the impurities (Rocchetti et al., 2016).

Several studies have discussed that the kinetics of indium extraction with D2EHPA from sulfate solutions is faster than that of iron extraction (Ruan et al., 2012; Yang et al., 2014; Chang et al., 2016). To study the possibility of increasing $\mathrm{In} / \mathrm{Fe}$ selectivity by operating the extraction step at non-equilibrium, the residence time in the mixer was decreased to 5 min in Experiment L-LE4 (Table 4). The extent of iron extraction and other impurities decreased without any significant decrease in indium extraction. This increased the purity of indium in the organic phase from $46.9 \%$ to $56.1 \%$. Because the increase in purity was quite low, it is likely that the In/Fe selectivity problem cannot be overcome by further shortening the residence time.

Thus, it is concluded that the separation of indium from iron and aluminum must be achieved by selective stripping. Consequently, the extracted impurities accumulate in the organic phase during the operation and need to be removed occasionally. In particular, iron is known to be difficult to strip. Among the typical mineral acids, stripping is easiest in a concentrated $\mathrm{HCl}$ medium (for example, $5 \mathrm{M}$, Alberts and Dorfling, 2013). Some iron can be stripped in a concentrated $\mathrm{H}_{2} \mathrm{SO}_{4}$ medium; however, the equilibrium is not as favorable 
as with $\mathrm{HCl}$. Liu et al. (2014) showed that stripping may be performed quantitatively by using a reducing mixture of $\mathrm{Na}_{2} \mathrm{SO}_{3}$ and $\mathrm{H}_{2} \mathrm{SO}_{4}$, and Singh et al. (2006 and 2013) suggested oxalic acid as the stripping agent. The kinetics with oxalic acid is slow, and quantitative stripping in a single stage requires $20 \mathrm{~min}$. The process can be accelerated by increasing the temperature. An interesting alternative to normal hydrometallurgical stripping of iron is galvanic stripping in which steel scrap (Sun and O'Keefe, 2002) or metallic zinc (Gu et $a l ., 2000)$ is used as the reducing agent. Galvanic stripping is believed to be economical and recovers stripped iron in a saleable form.

One additional possibility to overcome the $\mathrm{In} / \mathrm{Fe}$ selectivity problem is adding some reducing agent to the solution before performing the liquid-liquid extraction (Fortes and Benedetto, 1998; Li et al., 2015). Fe(III) was reduced to Fe(II), which was weakly extracted with D2EHPA. The drawbacks to this type of additional process step include increased cost and some indium loss.

\subsection{Selective ITO scraping-based process}

\subsubsection{Mechanical scraping of the ITO film}

Analyses of the two samples of knife-scraped "black material" from the surface of the LCD glass are presented in Table 5. The indium content in the material is very high but varies because the content in the second sample is approximately double of that in the first sample. The tin content in the material was approximately one-tenth of the indium content, indicating that indium and tin originated exclusively from the ITO film. The concentrations of other metals in the two samples were a maximum of $6.33 \mathrm{~g} / \mathrm{kg}$. The contents of indium 
and tin are similar to the ones obtained via cylindrical grinding apparatuses (Chen et al., 2017), considering that here the liquid crystals were removed prior to scraping. The contents of indium and tin from all the six metals $(\% I n+S n$-column in Table 5) indicate that metal content in the "black material" was mostly ITO.

Table 5. Composition of "black material" scraped from the surface of the LCD panels.

\begin{tabular}{clllllll}
\hline Sample ID & In & Sn & Al & Fe & Cu & Zn & \% In + Sn \\
\hline ITO1 & 188 & 18.1 & 3.67 & 1.14 & 6.33 & 0.08 & $94.8 \%$ \\
ITO2 & 374 & 36.0 & 4.22 & 1.56 & 0.38 & 0.03 & $98.5 \%$ \\
\hline
\end{tabular}

Note: Concentrations measured by wet combustion + the ICP-MS method and given as $\mathrm{g} / \mathrm{kg}$.

Six LCD glass samples were taken for systematic study using the ITO film scraping method (Table 6). The samples and the performance of the scrapings were examined using the following quantities: area density of the LCD glass $\left(\rho_{\mathrm{A}}, \mathrm{g} / \mathrm{m}^{2}\right)$, indium content per unit area $\left(\mathrm{In}^{0}, \mathrm{mg} / \mathrm{m}^{2}\right)$, indium content per unit area after scraping $\left(\mathrm{In}^{1}, \mathrm{mg} / \mathrm{m}^{2}\right)$, yield of indium in from scraping $\left(Y_{\mathrm{In}}, \%\right)$, and indium content in the scraped material $\left(q_{\mathrm{In}}, \mathrm{g} / \mathrm{kg}\right)$. The area density was determined by weighing an accurately metered area, and indium content per unit area was determined by analyzing the metered and weighed area. The yield of indium was calculated from analyses before and after scraping, and indium the content in the scraped material was determined according to the solid sample analysis described in Section 2.2.

Studies on the ITO film scraping method revealed large variations in the LCD panels in terms of their area density and indium content per unit area (Table 6). The area density varied from 1170 to $1820 \mathrm{~g} / \mathrm{m}^{2}$ (average $1600 \mathrm{~g} / \mathrm{m}^{2}$ ), and the indium content per unit area 
varied from 164 to $897 \mathrm{mg} / \mathrm{m}^{2}$ (average $503 \mathrm{mg} / \mathrm{m}^{2}$ ). Typically, indium yields from the invented scraping method were over $91 \%$, with the highest yield of $99.7 \%$, although one sample yielded only $20.5 \%$ indium. The range of yields indicates significant variations in terms of how the ITO film is attached to the glass surface in different panels. Large variations were also observed for the indium concentration in the scraped materials compared to the typical values of over $160 \mathrm{~g} / \mathrm{kg}$, with one sample measuring only 9.50 $\mathrm{g} / \mathrm{kg}$.

Table 6. Characterization and scraping of "black material" from six different LCD glass samples.

\begin{tabular}{cccccc}
\hline Sample ID & $\boldsymbol{\rho}_{\mathbf{A}}, \mathbf{g} / \mathbf{m}^{\mathbf{2}}$ & $\mathbf{I n}^{\mathbf{0}}, \mathbf{~} \mathbf{g} / \mathbf{m}^{\mathbf{2}}$ & $\mathbf{I n}^{\mathbf{1}}, \mathbf{~} \mathbf{g} / \mathbf{m}^{\mathbf{2}}$ & $\boldsymbol{Y}_{\mathbf{I n}}, \boldsymbol{\%}$ & $\boldsymbol{q}_{\mathbf{I n}}, \mathbf{g} / \mathbf{k g}$ \\
\hline LCD5 & 1820 & 897 & 76.8 & 91.4 & 198 \\
LCD6 & 1640 & 742 & 21.3 & 97.1 & 176 \\
LCD7 & 1670 & 805 & 2.70 & 99.7 & 167 \\
LCD8 & 1660 & 164 & 2.00 & 98.8 & 31.5 \\
LCD9 & 1620 & 197 & 156 & 20.5 & 51.7 \\
LCD10 & 1170 & 212 & 104 & 51.1 & 9.50 \\
\hline Average & 1600 & 503 & 60.5 & 76.4 & 106 \\
\hline
\end{tabular}

\subsubsection{Leaching}

Even though the metal content in the "black material" scraped from the LCD glass was found to consist almost exclusively of ITO, there were significant amounts of non-metallic materials present. Therefore, purification is required to obtain pure indium, and the suggested route is $\mathrm{H}_{2} \mathrm{SO}_{4}$ leaching followed by cementation.

Indium yield and purity, the most important performance indicators of leaching, were strongly influenced by the scraper used (Table 7). With a ceramic scraper, the indium yield 
obtained from leaching was $88.6 \%$ (52-67\% with a steel scraper), and the purity of the leachate was over $99 \%$. The lower purity with the steel scraper (96-98\%) was attributed to iron (Table 7). Thus, some steel was released from the scraper into the "black material" during scraping. During the scraping experiments, it was observed that the ITO film layer was removed more quickly and easily using the ceramic scraper.

Table 7. Leaching the "black material" scraped from the surface of the LCD panel with $\mathrm{H}_{2} \mathrm{SO}_{4}$.

\begin{tabular}{cccccccccccc}
\hline Exp. ID & $\boldsymbol{c}_{\text {acid }}, \mathbf{M}$ & $\boldsymbol{T}$, ${ }^{\circ} \mathbf{C}$ & Scraper & $\boldsymbol{c}_{\text {In }}$ & $\boldsymbol{c}_{\text {Sn }}$ & $\boldsymbol{c}_{\text {Al }}$ & $\boldsymbol{c}_{\text {Fe }}$ & $\boldsymbol{c}_{\text {Cu }}$ & $\boldsymbol{c}_{\mathbf{Z n}}$ & $\boldsymbol{Y}_{\text {In }}, \boldsymbol{\%}$ & $\boldsymbol{P}_{\text {In }}, \boldsymbol{\%}$ \\
\hline L6 & 1 & 50 & Steel & 3980 & 18.5 & 6.90 & 64.6 & 2.10 & 2.90 & 66.3 & 97.7 \\
L7 & 2 & 50 & Steel & 4000 & 72.5 & 6.80 & 66.5 & 2.40 & 2.70 & 66.6 & 96.4 \\
L8 & 1 & 25 & Steel & 3190 & 5.80 & 5.60 & 43.3 & 3.30 & 1.70 & 52.7 & 98.2 \\
L9 & 2 & 50 & Ceramic & 5320 & 35.5 & 3.60 & 3.20 & 3.00 & 0.90 & 88.6 & 99.1 \\
\hline
\end{tabular}

Note: Concentrations in $\mathrm{mg} / \mathrm{L}$. The yield of indium was calculated according to $15 \mathrm{wt} .-\%$ concentration in the scraped material, which was chosen as the characteristic quantity based on the systematic scraping experiments shown in Table 6.

The higher grade "black material" obtained using the ceramic scraper also improved the kinetics of leaching with sulfuric acid (Fig. 1). Using the same leaching conditions, it required approximately 15 to $20 \mathrm{~h}$ to achieve equilibrium when using the steel-scraped material but less than $4 \mathrm{~h}$ when using the ceramic-scraped material. The acid concentration was found to have a much stronger effect on the leaching kinetics than temperature. Apparently, mass transfer is not a limiting factor, and the chemical reactions of $\operatorname{In}_{2} \mathrm{O}_{3}$ and $\mathrm{SnO}_{2}$ in ITO with $\mathrm{H}_{2} \mathrm{SO}_{4}$ (Eqs. 10 and 11) determine the leaching kinetics.

It is possible that the easier removal of the ITO film leads to a lower amount of organic impurities in the "black material", which consequently leads to increased yields and faster kinetics because the organic material can block the contact between the ITO and $\mathrm{H}_{2} \mathrm{SO}_{4}$. 
Another possible explanation is that more glass is scraped with the steel scraper, and it hinders leaching similar to the organic material.

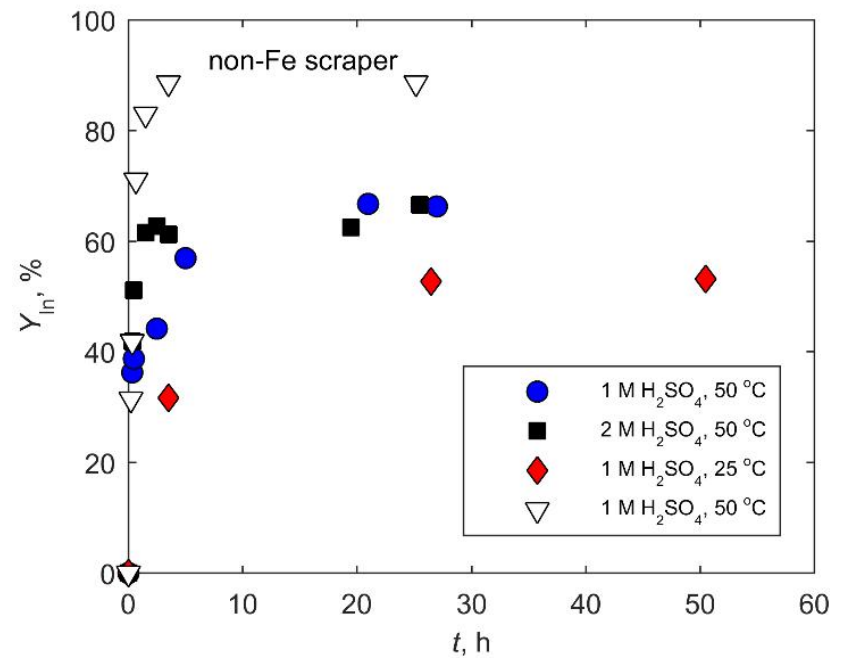

Figure 1. Leaching scraped material from the surface of the LCD panel with $\mathrm{H}_{2} \mathrm{SO}_{4}$. $\mathrm{L} / \mathrm{S}=50 \mathrm{~mL} / 2 \mathrm{~g}$.

\subsection{Suggested flowsheets}

The two flowsheets designed for the recovery of indium from LCD panel waste are shown in Figure 2. The conventional process starts with manual removal of the polarizing filter. This is mandatory as this organic material jams the equipment and hinders flow of the phases if it continues to the liquid-liquid extraction step. Removal of the polarizing filters is not required in the selective ITO scraping-based process, and as was observed it is a challenging step that requires human work, and/or chemical or heat treatment.

After manual dismantling, both suggested processes include mechanical pretreatment and similar leaching steps. In the leaching stage of the conventional process, the indium yields 
are $69-85 \%$. The higher yield (89\%) achieved using the selective ITO scraping based process makes it more attractive.

Additionally, the cementation step is similar in both processes. Both processes are able to provide over $99 \%$ pure indium solutions for cementation. It is expected based on Rocchetti et al. (2016) that indium is further purified during cementation, meaning that indium metal at above $99 \%$ purity is expected from both suggested processes. While cementation can be performed using very dilute indium solutions (Rocchetti et al., 2016), and both processes studied here are thus applicable, the selective ITO scraping-based process is preferred because it yields a more concentrated feed to cementation. This results in lower volumes and lower equipment and pumping costs. 


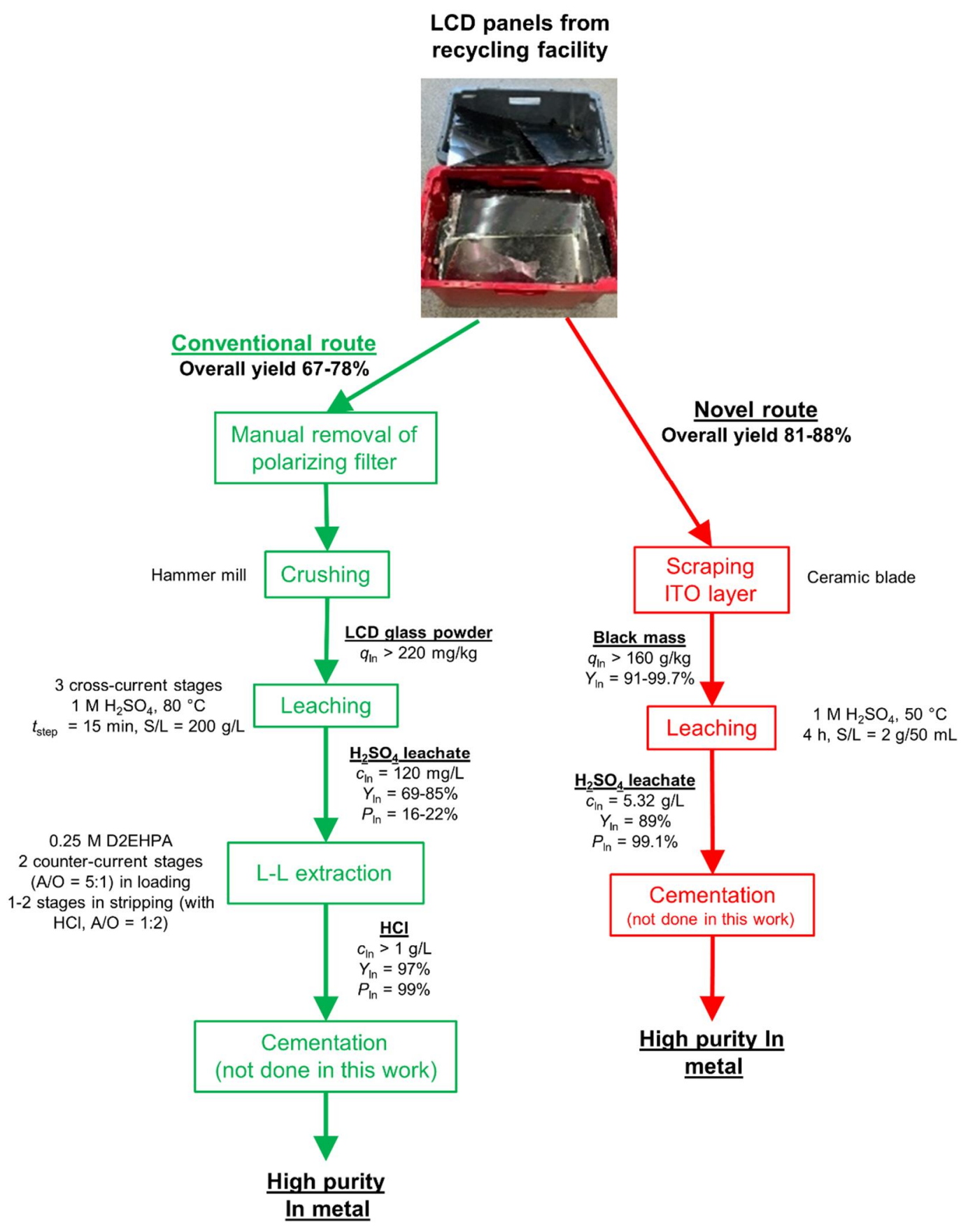

Figure 2. Two alternative processes for recovering indium from LCD panel waste. 
The overall yields obtained using the conventional process and the selective ITO scrapingbased process are $67-78 \%$ 81-88\% (Figure 2). The most significant difference between the processes is that the latter eliminates the need for the liquid-liquid extraction step and the step of removal of the polarizing filter. While liquid-liquid extraction is known to be very efficient for purifying and concentrating metals, it is expensive. Moreover, removing the polarizing filter is difficult but mandatory in this process. Some pyrolytic or heating methods could perhaps be used to burn the filter or to make it easier to remove. In this study, heating prior to manual removal was tested, but technical success depended considerably on the individual panel. If the polarizing filter needs to be manually removed, like it was done in this study, it results in significant labor costs, and no automatic mechanical removal method has yet been suggested.

Finally, the selective ITO scraping-based process requires at least ten times less leaching acid than the conventional process. Only the "black material" is processed in the selective ITO scraping-based process, whereas the conventional process handles large amounts of glass (compared to the amount of indium).

From the qualitative discussion above, it can be concluded that there are several features suggesting that the selective ITO scraping-based process offers considerable economic and technical benefits compared with the conventional process. 


\section{Conclusions}

Two alternative processes for recovering pure indium from LCD panel waste were designed and verified by bench-scale experiments with authentic raw material. The first designed process consisted of different unit processes that have been described previously in the literature. However, the entire process has not been previously demonstrated using a similar flowsheet, or on a similar scale using authentic raw materials. The conventional process consists of manual removal of polarizing filters, hammer mill crushing of the glass material, cross-current $\mathrm{H}_{2} \mathrm{SO}_{4}$ leaching, and liquid-liquid extraction purification of indium with D2EHPA. In the novel alternative to the conventional process, the ITO film layer is manually scraped from the glass panels and leached with $\mathrm{H}_{2} \mathrm{SO}_{4}$. Experiments conducted in this study produced overall yields for indium of over $70 \%$ using the conventional process, over $80 \%$ using the selective ITO scraping-based process, and both processes were able to produce $99 \%$ pure indium solutions. From this type of solution, high-purity metallic indium can be cemented. Qualitative comparison of the processes revealed that the selective ITO scraping-based process is technically and probably economically more feasible than the conventional process because it uses smaller amounts of leaching acid and does not require the fairly expensive and complicated polarizing filter removal and liquidliquid extraction steps.

\section{Acknowledgements}

Kuusakoski Recycling is acknowledged for supplying authentic LCD panel waste. 


\section{References}

Alberts, E., Dorfling, C., 2013. Stripping conditions to prevent the accumulation of rare earth elements and iron on the organic phase in the solvent extraction circuit at Skorpion Zinc, Miner. $\quad$ Eng. 40, 48-55, http://dx.doi.org/10.1016/j.mineng.2012.09.005

Argenta, A.B., Reis, C.M., Mello, G.P., Dotto, G.L., Tanabe, E.H., Bertuol, D.A., 2017. Supercritical $\mathrm{CO}_{2}$ extraction of indium present in liquid crystal displays from discarded cell phones using organic acids. J. Supercrit. Fluids 120, 95-101. https://doi.org/10.1016/j.supflu.2016.10.014

Assefi, M., Maroufi, S., Nekouei, R.K., Sahajwalla, V., 2018. Selective recovery of indium from scrap LCD panels using macroporous resins. J. Clean. Prod. 180, 814-822. https://doi.org/10.1016/j.jclepro.2018.01.165

Baldé, C.P., Forti V., Gray, V., Kuehr, R., Stegmann,P., 2017. The Global E-waste Monitor - 2017, United Nations University (UNU), International Telecommunication Union (ITU) \& International Solid Waste Association (ISWA), Bonn/Geneva/Vienna.

Boundy, T., Boyton, M., Taylor, P., 2017. Attrition scrubbing for recovery of indium from waste liquid crystal display glass via selective comminution. J. Clean. Prod. 154, 436444. https://doi.org/10.1016/j.jclepro.2017.04.038

Brubaker, C.H., 1955. The Hydrolysis of Tin(IV) in Sulfuric Acid, J. Am. Chem. Soc. 77, 5265-5268.

Böni, H., Widmer, R., 2011. Disposal of Flat Panel Display Monitors in Switzerland, EMPA, St. Gallen, report.

Böni, H., Wäger, P., Figi, R., 2015 (in German). Rückgewinnung von kritischen Metallen wie Indium und Neodym aus Elektronikschrott auf der Stufe der manuellen und mechanischen Vorbehandlung, Recycling und Rohstoffe 8.

Chang, J., Zhang, L., Du, Y., Peng, J., Hu, G., Chen, J., Srinivasakannan, C., 2016. Separation of indium from iron in a rotating packed bed contactor using Di-2ethylhexylphosphoric acid, Sep. Purif. Technol. 164, 12-18, http://dx.doi.org/10.1016/j.seppur.2016.03.017

Chen, Y., Zhang, L., Xu, Z., 2017. Vacuum pyrolysis characteristics and kinetic analysis of liquid crystal from scrap liquid crystal display panels. J. Hazard. Mater. 327, 55-63. https://doi.org/10.1016/j.jhazmat.2016.12.026

European Chemicals Agency, 2010. Background document for Diarsenic trioxide, report.

European Commission, 2017. Communication from the commission to the European parliament, the council, the European economic and social committee and the committee of the regions on the 2017 list of Critical Raw Materials for the EU. https://eur-lex.europa.eu/legal-content/EN/TXT/?uri=CELEX:52017DC0490 
Ferella, F., Belardi, G., Marsilii, A., De Michelis, I., Vegliò, F., 2017. Separation and recovery of glass, plastic and indium from spent LCD panels, Waste Manage. 60, 569581. https://doi.org/10.1016/j.wasman.2016.12.030

Fontana, D., Forte, F., De Carolis, R., Grosso, M., 2015. Materials recovery from waste liquid crystal displays: A focus on indium, Waste Manage. 45, 325-333. http://dx.doi.org/10.1016/j.wasman.2015.07.043

Fortes, M.C.B., Benedetto, J.S., 1998. Separation of indium and iron by solvent extraction, Miner. Eng. 11, 447-451, https://doi.org/10.1016/S0892-6875(98)00023-5

Graedel, T.E., Allwood, J., Birat, J.-P., Buchert, M., Hagelueken, C., Reck, B.K., et al., 2011. Recycling Rates of Metals: A Status Report - A Report of the Working Group on Global Metal Flows to the International Resource Panel, UNEP.

Gu, H., Chang, C.-M., Barrera-Godinez, J.A., O’Keefe, T. J., 2000. Preliminary design of a solvent extraction process for the galvanic stripping of iron from D2EHPA, Miner. Metall. Proc. 17, 16-22.

Hasegawa, H., Rahman, I.M.M., Egawa, Y., Sawai, H., Begum, Z.A., Maki, T., Mizutani, S., 2013. Recovery of indium from end-of-life liquid-crystal display panels using aminopolycarboxylate chelants with the aid of mechanochemical treatment, Microchem. J. 106, 289-294. https://doi.org/10.1016/j.microc.2012.08.010

Hughes, M.A., Kuipa, P.K., 1996. Kinetics and Mechanism of Copper Extraction with Dialkylphosphoric Acids and Hydroxyoximes Studied by a Rotating Diffusion Cell, Ind. Eng. Chem. Res. 35, 1976-1984, DOI: 10.1021/ie950465b

Indium Corporation, 2018. Indium Sulfate Product Data Sheet, http://www.indium.com/inorganic-compounds/indium-compounds/indium-sulfate/, accessed 13.2.2018.

Javad Jowkar, M., Bahaloo-Horeh, N., Mousavi, S.M., Pourhossein, F., 2018. Bioleaching of indium from discarded liquid crystal displays, J. Clean. Prod. 180, 417-429, https://doi.org/10.1016/j.jclepro.2018.01.136

Lee, C.H. Jeong, M.K. Kilicaslan, M.F. Lee, J.H. Hong, H.S., Hong S.J., 2013. Recovery of indium from used LCD panel by a time efficient and environmentally sound method assisted HEBM, Waste Manage. 33, 730-734. https://doi.org/10.1016/j.wasman.2012.10.002

Lee, S. J., Cooper, J., 2008. Estimating regional material flows for LCDs. Proceedings of the IEEE international symposium on electronics and the environment ISEE (May 2008), San Francisco, CA, 1-6. doi: 10.1109/ISEE.2008.4562907

Li, X., Wei, C., Deng, Z., Li, C., Fan, G., Rong, H., Zhang, F., 2015. Extraction and separation of indium and copper from zinc residue leach liquor by solvent extraction, Sep. Purif. Technol. 156, 348-355, https://doi.org/10.1016/j.seppur.2015.10.021

Liu, Y., Nam, S.-H., Lee, M., 2014. Stripping of Fe(III) from the Loaded Mixture of D2EHPA and TBP with Sulfuric Acid Containing Reducing Agents, B. Kor. Chem. Soc. 35, 2109-2113, http://dx.doi.org/10.5012/bkcs.2014.35.7.2109 
Lokanc, M., Eggert, R., Redlinger, M., 2015. The Availability of Indium: The Present, Medium Term, and Long Term, National Renewable Energy Laboratory (NREL), www.nrel.gov/publications.

Ma, E., Xu, Z., 2013. Technological process and optimum design of organic materials vacuum pyrolysis and indium chlorinated separation from waste liquid crystal display panels, J. Hazard. Mater. 263, 610-617, https://doi.org/10.1016/j.jhazmat.2013.10.020

Mohapatra, D., Kim, H.-I., Nam, C.-W., Park, K.-H., 2007. Liquid-liquid extraction of aluminium(III) from mixed sulphate solutions using sodium salts of Cyanex 272 and D2EHPA, Sep. Purif. Technol. 56, 311-318, http://dx.doi.org/10.1016/j.seppur.2007.02.017

Puigdomenech, I., 2004. Hydra/Medusa - Chemical Equilibrium Database and Plotting Software, KTH - Chemistry, Stockholm, Sweden.

Raatz, S., Klapper, P., 2013. Using interfacial tension measurements to analyze the mechanism of zinc extraction with D2EHPA, Hydrometallurgy 134, 19-25, http://dx.doi.org/10.1016/j.hydromet.2013.01.007

Rasenack, K., Goldmann, D., 2014 (in German). Herausforderungen des IndiumRecyclings aus LCD-Bildschirmen und Lösungsansätze, Recycling und Rohstoffe 7, 205-215.

Rocchetti, L., Veglio, F., Kopacek, B., Beolchini, F., 2013. Environmental Impact Assessment of Hydrometallurgical Processes for Metal Recovery from WEEE Residues Using a Portable Prototype Plant, Envir. Sci. Tech. 47, 1581-1588. DOI: 10.1021/es302192t

Rocchetti, L., Amato, A., Beolchini, F., 2016. Recovery of indium from liquid crystal displays, J. Clean. Prod. 116, 299-305, http://dx.doi.org/10.1016/j.jclepro.2015.12.080

Rocchetti, L., Amato, A., Fonti, V., Ubaldini, S., De Michelis, I., Kopacek, B., Veglio, F., Beolchini, F., 2015. Cross-current leaching of indium from end-of-life LCD panels, Waste Manage. 42, 180-187, https://doi.org/10.1016/j.wasman.2015.04.035

Ruan, J., Guo, Y., Qiao, Q., 2012. Recovery of indium from scrap TFT-LCDs by solvent extraction, Procedia Environ. Sci. 16, 545-551, https://doi.org/10.1016/j.proenv.2012.10.075

Sato, T., Sato, K., 1992. Liquid-liquid extraction of indium (III) from aqueous acid solutions by acid organophosphorus compounds. Hydrometallurgy 30, 367-383, https://doi.org/10.1016/0304-386X(92)90094-G

Singh, D.K., Mishra, S.L., Singh, H., 2006. Stripping of iron (III) from the D2EHPA + TBP extract produced during uranium recovery from phosphoric acid by oxalic acid. Hydrometallurgy 81, 214-218, https://doi.org/10.1016/j.hydromet.2005.12.006

Singh, D.K., Yadav, K., Singh, H., 2013. Extraction and Stripping Behavior of Iron (III) from Phosphoric Acid Medium by D2EHPA Alone and Its Mixtures with TBP/TOPO, Sep. Sci. Technol. 48, 1556-1564, http://dx.doi.org/10.1080/01496395.2012.753084 
Sun, J., O' Keefe, T.J, 2002. An evaluation of steel scrap as a reducing agent in the galvanic stripping of iron from D2EHPA, Miner. Eng. 15, 177-185. http://dx.doi.org/10.1016/S0892-6875(02)00004-3

United States Geological Survey, Mineral Commodity Summaries 2017.

Virolainen, S., 2013. Hydrometallurgical recovery of valuable metals from secondary raw materials, Doctoral Thesis, Lappeenranta University of Technology. http://urn.fi/URN:ISBN:978-952-265-525-7

Virolainen, S., Paatero, E., Ibana, D.C., 2011a. Recovery of Indium from LCD screens, in: $19^{\text {th }}$ International Solvent Extraction Conference ISEC 2011, Santiago, Chile.

Virolainen, S., Paatero, E., Ibana, D., 2011b. Recovery of indium from indium tin oxide by solvent extraction, Hydrometallurgy 107, 56-61, https://doi.org/10.1016/j.hydromet.2011.01.005

Wang, H., Gu, Y., Wu, Y., Zhang, Y.-N., Wang, W., 2015. An evaluation of the potential yield of indium recycled from end-of-life LCDs: a case study in China, Waste Manage. 46, 480-487. https://doi.org/10.1016/j.wasman.2015.07.047

Wang, H.Y., 2009. A study of the effects of LCD glass sand on the properties of concrete, Waste Manage. 29, 335-341. https://doi.org/10.1016/j.wasman.2008.03.005

Werner, T.T., Mudd, G.M., Jowitt, S.M., 2017. The world's by-product and critical metal resources part III: A global assessment of indium, Ore geol. Rev. 86, 939-956. https://doi.org/10.1016/j.oregeorev.2017.01.015

Yang, J., Ekberg, C., Retegan, T., 2013. Indium recovery from discarded LCD panel glass by solvent extraction, Hydrometallurgy 137, 68-77, https://doi.org/10.1016/j.hydromet.2013.05.008

Wiberg, N., Holleman, A.F., Wiberg, E. (Eds.), 2001. Inorganic Chemistry, Academic Press, San Diego.

Yang, J., Ekberg, C., Retegan, T., 2014. Optimization of Indium Recovery and Separation from LCD Waste by Solvent Extraction with Bis(2-ethylhexyl) Phosphate (D2EHPA), Int. J. Chem. Eng. 2014, Article ID 186768, http://dx.doi.org/10.1155/2014/186768

Zhang, L., Chen, Y., Xu, Z., 2018. Controllable Formation of Carbon Fiber in Pyrolysis Process of Liquid Crystals from Waste LCD Panels and Indium Recovery by Vacuum in Situ Reduction with Carbon Fiber. ACS Sustainable Chem. Eng. 6, 541-550. https://doi.org/10.1021/acssuschemeng.7b02828

Zhang, L., Xu, Z., 2017. C, H, Cl, and In Element Cycle in Wastes: Vacuum Pyrolysis of PVC Plastic To Recover Indium in LCD Panels and Prepare Carbon Coating. ACS $\begin{array}{llll}\text { Sustainable } & \text { Chem. } & \text { Eng. } & \text { 8918-8929. }\end{array}$ https://doi.org/10.1021/acssuschemeng.7b01737 
Zhang, L., Wu, B., Chen, Y., Xu, Z., 2017a. Energy and valuable resource recovery from waste liquid crystal display panels by an environment-friendly technological process: Pyrolysis of liquid crystals and preparation of indium product. J. Clean. Prod. 162, 141152. https://doi.org/10.1016/j.jclepro.2017.06.031

Zhang, L., Wu, B., Chen, Y., Xu, Z., 2017b. Treatment of liquid crystals and recycling indium for stripping product gained by mechanical stripping process from waste liquid crystal display panels. J. Clean. Prod. 162, 1472-1481. https://doi.org/10.1016/j.jclepro.2017.06.159 